\title{
Graphene-based sorbents for iodine-129 capture and sequestration
}

\author{
Spencer M. Scott, Tao Hu, Tiankai Yao, Guoqing Xin, and Jie Lian* \\ Department of Mechanical, Aerospace and Nuclear Engineering, Rensselaer Polytechnic \\ Institute, 110, 8th Street, Troy, New York, 12180, US \\ *Corresponding Author. Tel: 518 276-6081. Email: lianj@rpi.edu
}

\begin{abstract}
The capture and sequestration of Iodine-129 $\left({ }^{129} \mathrm{I}\right)$, a long-lived byproduct of nuclear fission, is essential to the implementation of advanced nuclear fuel cycles and effective nuclear waste management. Current state-of-the-art technologies inherently require silver to bind iodine, e.g., silver-loaded silica aerogels or silver-loaded zeolite (AgZ), which are very expensive and an environmental concern. It is highly desirable to develop alternative cost-effective adsorbents for iodine capture and sequestration. Herein, we report graphene-based nanomaterials including graphene powder and graphene aerogel as novel iodine sorbents showing exceptional adsorption capability and kinetics. By measuring iodine sorption capacities and uptake rates in an $\mathrm{I}_{2(\mathrm{~g})}$ saturated environment, graphene sorbents display impressive iodine sorption capacities with powdered samples achieving mass gains in excess of 85 mass\%, and aerogels exceeding 100\% mass gains. A direct correlation among specific surface area, defect concentration, and maximum sorption capacity has been established, and the sorption kinetics of the graphene for iodine capture was determined.
\end{abstract}

\section{Introduction}

Iodine-129 $\left(\mathrm{I}^{129}\right)$, a long-lived $\left(1.6 \times 10^{7}\right.$ year half-life $)$ radionuclide, is of significant concern to the implementation of spent nuclear fuel reprocessing [1]. This can be attributed to the environmental mobility and biological affinity of iodine, which when combined with the radioactive nature of ${ }^{129} \mathrm{I}$, presents a threat to public safety due to the potential for serious health issues [2]. Due to these concerns, the Environmental Protection Agency (EPA) has implemented strict regulations on the release of ${ }^{129}$ I from the reprocessing facilities, which require an effective 
capture efficiency in excess of 99\% (Decontamination Factor > 167) [3]. This has created a demand for iodine sorbents and waste forms which will be suitable for use in reprocessing systems and geologic disposal [4].

The most common methods of iodine management involve ${ }^{129} \mathrm{I}_{2(\mathrm{~g})}$ being passed through silverexchanged-zeolite (AgZ), which due to its silver content is highly selective for elemental iodine $[5,6]$. However, due to issues associated with densification into a durable waste form, and the relatively high cost of silver, implementation has lagged. Other sorbents currently being investigated include Ag-functionalized silica aerogels, and chalcogen-based aerogels, both of which have been relatively successful for iodine capture but may be costly to produce, either due to fabrication techniques or precursor materials $[7,8]$.

Graphene, the two-dimensional basal plane of graphite, has become the focus of extensive interest for a wide range of applications including composite materials, semiconductors, and energy storage, due to its impressive mechanical, electrical, and thermal properties $[9,10]$. However, the extremely-large theoretical specific surface area $\left(2630 \mathrm{~m}^{2} \mathrm{~g}^{-1}\right)$ for single layer graphene, in combination with its highly controllable defect and functional group concentration, has generated interests for graphene as a sorbent material for gasses, albeit primarily for potential gas detectors $[11,12]$.

This work presents graphene-based materials including graphene powder and aerogel as potential sorbents for ${ }^{129} \mathrm{I}$ in spent nuclear fuel reprocessing off-gas, and investigates the sorption capacities of several varieties of graphene for $I_{2(g)}$ in a saturated iodine environment. The synthesis and characterization techniques for the graphene sorbents are provided, in addition to analysis on the sorption capacity and thermal stability of the iodine-loaded samples. The correlation among surface area, defect concentration, and temperature as to how they affect the sorption/desorption interaction between graphene and elemental iodine was determined.

The graphene-based sorbents address several key challenges associated with the capture of ${ }^{129} \mathrm{I}$ in the reprocessing of spent nuclear fuel. The most prominent challenge, the reliance on silver in sorbent materials, presents a significant financial hurdle facing several current technologies. The high specific surface area of graphene-based materials enable improvements in the maximum sorption capacity and rapid kinetics of iodine adsorption over conventional methods which utilize a chemical affinity for iodine as opposed to physical adsorption of iodine. The relatively simple fabrication of graphene may also address issues associated with some of the more highly 
engineered sorbent materials, which require more complicated processes to synthesize [6-9]. Thus, graphene-based absorbents are more cost effective for iodine capture and sequestration.

\section{Experimental Section}

\subsection{Graphene Synthesis}

Graphite oxide (GO) was synthesized using a modified Hummers method [13]. Graphite flake (10 g) was mixed with sodium nitrate $(5 \mathrm{~g})$ and concentrated sulfuric acid (18 M, $230 \mathrm{~mL})$. The mixture was carefully stirred in an ice bath $\left(0{ }^{\circ} \mathrm{C}\right)$, and potassium permanganate $(30 \mathrm{~g})$ was slowly added to the solution to ensure that the temperature did not exceed $20{ }^{\circ} \mathrm{C}$. The solution was then heated to $35{ }^{\circ} \mathrm{C}$ for 30 minutes. Deionized water $(460 \mathrm{~mL})$ was added and the solution was then heated to $98{ }^{\circ} \mathrm{C}$ for 15 mins. A weak hydrogen peroxide solution was then added ( $3 \mathrm{wt}$, $710 \mathrm{~mL}$ ). A series of centrifugation (3200 rpm, $5 \mathrm{mins}$ ) with repeated deionized water, dilute hydrochloric acid, and ethanol washing produced the GO powder which was vacuum dried at 40 ${ }^{\circ} \mathrm{C}$ for 12 hours.

Thermal shock graphene powder was obtained through a thermal exfoliation process, in which GO powder (200 mg) was loaded in an argon filled, quartz tube furnace (GSL1100X, MTI, USA) at $1050{ }^{\circ} \mathrm{C}$ for 30 seconds [14]. Pristine graphene powder, which demonstrated remarkably high specific surface area and defect concentration was comercially avaible and purchased from Shanghai Xinchi Energy Technology Co. Ltd. Pristine graphene powder was annealed to reduce the defect concentration, and in turn the specific surface area, through the use of an electric furnace [15]. By annealing at $3000{ }^{\circ} \mathrm{C}$ defects were completely eliminated, resulting in a specific surface area reduction from $1272 \mathrm{~m}^{2} \mathrm{~g}^{-1}$ for the pristine highly defective graphene to $88.5 \mathrm{~m}^{2} \mathrm{~g}^{-1}$ for the defect-free graphene.

Graphene aerogels were synthesized using a hydrothermal process in which a GO solution $(3 \mathrm{mg} / \mathrm{ml})$ was heated in an autoclave at $120{ }^{\circ} \mathrm{C}$ for 10 hours to produce a graphene hydrogel [16]. The hydrogel was then freeze-dried overnight to produce the final aerogel.

\subsection{Iodine Uptake}

The graphene powders with different defect concentrations and surface areas samples were exposed to a saturated iodine environment through the use of a desiccator, in which solid iodine crystals were placed in lieu of the desiccant. Iodine uptake was determined through the change in mass of the tested samples before and after exposure to the saturated iodine environment. Due to 
the sublimation of iodine, the chamber quickly reached a saturated state, which helped drive the adsorption of $\mathrm{I}_{2(\mathrm{~g})}$ to reach the maximum sorption capacity within reasonable times. Exposure to a saturated-iodine environment allows for simple comparison of graphene to other sorbent materials currently being considered for iodine capture [17]. The iodine uptake experiment in a saturated iodine environment was also performed on graphene aerogel.

\subsection{Characterization Techniques}

Brunauer-Emmett-Teller (BET) surface area measurements were conducted using a Micromeritics ASAP 2000 instrument. The microstructure of samples was observed with a fieldemission SEM on a Zeiss Supra 55. Raman spectroscopy was carried out using a LabRAM

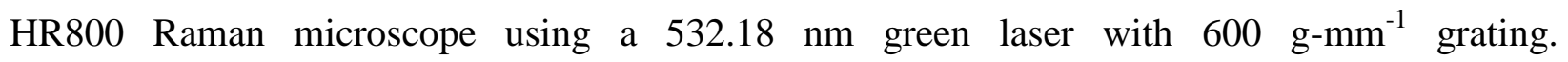
Thermogravimetric analysis (TGA) was carried out with a TA Instrument (TGA-Q50 instrument), and was utilized as a primary method for confirming the iodine uptake of the samples. TGA was also used to demonstrate the thermal stability of the sorbent, and indicate the temperature threshold for iodine desorption. XPS was conducted using a PHI 5000 Versa Probe system.

\section{Results and Discussion:}

Graphene shows great potential as an advanced absorbent material for capturing iodine with an extremely fast adsorption kinetics, as demonstrated by the iodine uptake results of the graphene powders (Figure 1A). SEM images (Figure 1B and Figure 1C) show the morphology of the graphene sheets and the presence of adsorbed iodine on graphene. The iodine in these images appears to adhere to the surface of the graphene, forming discrete particles. The mass gain curve shows an initial stage with a linear iodine uptake rate and very fast adsorption kinetics, followed by a gradual increase until reaching the maximum sorption capacity. The adsorption of iodine on the surface of graphene is further demonstrated by XPS (Fig. 1D and the inset), in which the characteristic peaks of iodine, I3d3, I3d5, and I4d are clearly observed at 630.8, 619.2, and 49.9 $\mathrm{eV}$, respectively. Quantitative analysis of XPS spectra reinforces the iodine uptake findings, with iodine peaks attributed to $45 \%$ of the total mass in pristine graphene powders after exposure. The total amount of adsorbed iodine in pristine graphene powders after exposure corresponds to $80 \%$ mass gain, consistent with the iodine uptake results. 

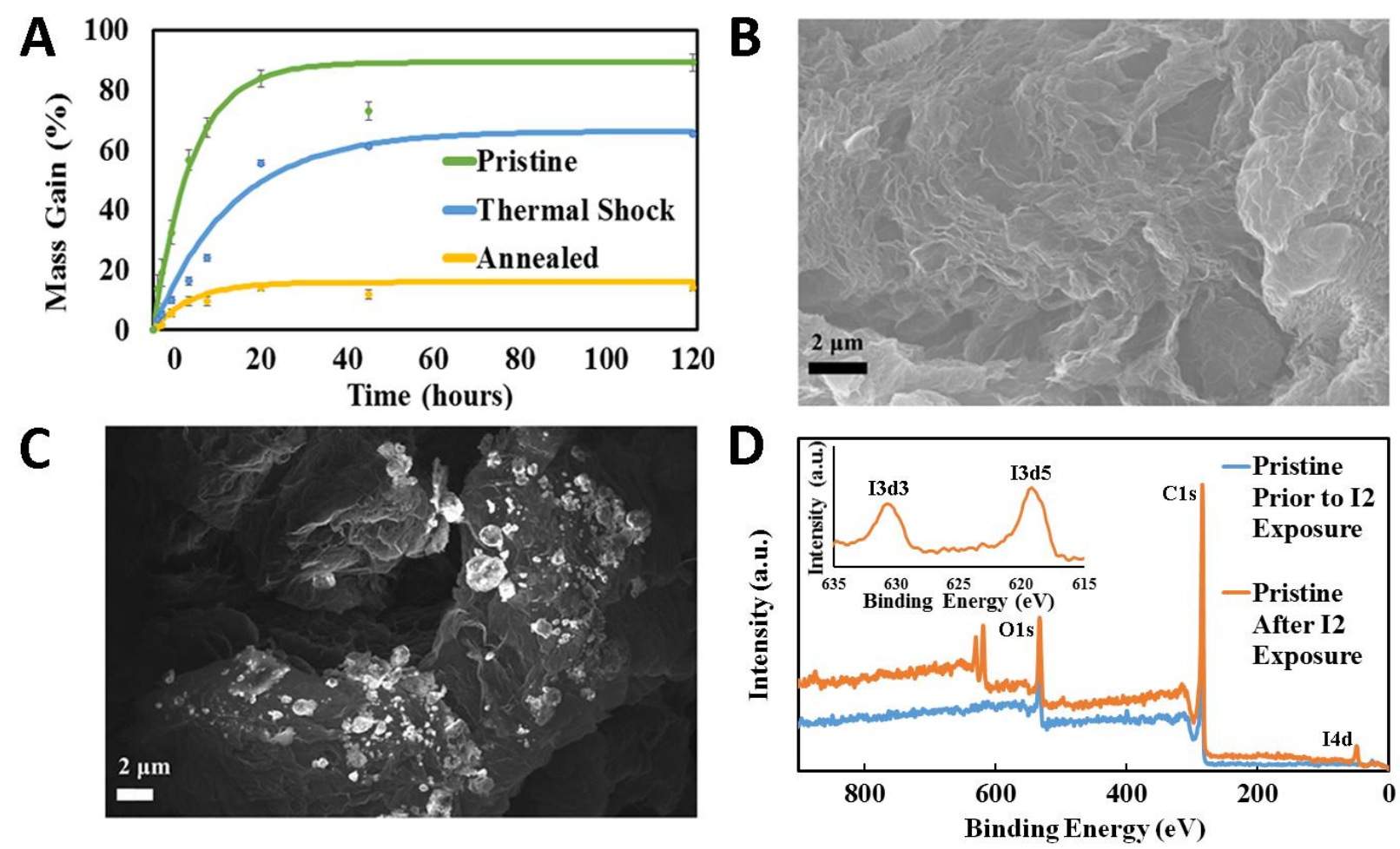

Figure 1. Iodine capture by graphene: (A) iodine uptake curves for the investigated graphene powders at $25{ }^{\circ} \mathrm{C}$; (B) SEM image of the pristine highly defective graphene; (C) iodine particulates upon absorbed on the surface of pristine graphene sheets; (D) XPS of pristine graphene before and after $\mathrm{I}_{2}$ exposure, indicating the presence of adsorbed iodine, XPS of I3d3 and I3d5 peaks (inset).

Table 1. Properties and iodine sorption capacities of the investigated graphene powders

\begin{tabular}{cccccc}
\hline Sample: & $\begin{array}{c}\text { Specific } \\
\text { Surface Area } \\
\left(\mathrm{m}^{2} \mathrm{~g}^{-1}\right)\end{array}$ & $\begin{array}{c}\text { Carbon to } \\
\text { Oxygen } \\
\text { Ratio }(\mathrm{C}: \mathrm{O})\end{array}$ & $\begin{array}{c}\text { Defect } \\
\text { Concentration } \\
\left(\mathrm{I}_{\mathrm{D}} / \mathrm{I}_{\mathrm{G}}\right)\end{array}$ & $\begin{array}{c}\text { Linear } \\
\text { Uptake Rate } \\
(\% / \mathrm{h})\end{array}$ & $\begin{array}{c}\text { Maximum } \mathrm{I}_{2} \\
\text { Sorption }\end{array}$ \\
\hline $\begin{array}{c}\text { Capacity }(\%) \\
\text { Thnealed }\end{array}$ & 88.5 & 44.45 & 0 & $1.2 \% \pm 0.1 \%$ & $15.8 \% \pm 1.4 \%$ \\
Shock & 400 & 4.52 & 1.11 & $2.2 \% \pm 0.2 \%$ & $66.2 \% \pm 0.8 \%$
\end{tabular}


The linear uptake rate and maximum $\mathrm{I}_{2}$ sorption capacity for graphene powders with different defect concentrations and surface areas are tabulated in Table 1. A direct relationship between specific surface area (Figure 2A) and the elemental iodine sorption capacity can be identified. For example, the 'thermal shock' graphene $\left(400 \mathrm{~m}^{2} \mathrm{~g}^{-1}\right)$ displayed a maximum sorption capacity $>65 \%$; while the annealed graphene sample $\left(88 \mathrm{~m}^{2} \mathrm{~g}^{-1}\right)$ displayed a maximum sorption capacity $>15 \%$. The exceptional performance of the 'pristine' highly defective graphene $\left(1272 \mathrm{~m}^{2} \mathrm{~g}^{-1}\right)$, with over $80 \%$ mass gain within the first 24-hours and a maximum sorption capacity exceeding $85 \%$, made it the optimal choice for further investigation regarding the adsorption kinetics. This demonstrates a direct relationship between specific surface area and iodine sorption capacity in graphene powders.

Raman spectroscopy of the samples (Figure 2B) indicates a direct relationship between the defect concentrations and the specific surface areas of the samples. The pristine highly defective graphene sample, which possessed the highest specific surface area, displayed the most intense D-band $\left(\sim 1350 \mathrm{~cm}^{-1}\right)$ as compared to its G-band $\left(\sim 1580 \mathrm{~cm}^{-1}\right)$, with an $\mathrm{I}_{\mathrm{D}} / \mathrm{I}_{\mathrm{G}}$ ratio of 1.32 , indicating the highest defect concentration of the samples measured. The thermal shock graphene with specific surface area of $400 \mathrm{~m}^{2} \mathrm{~g}^{-1}$ displays a notable D-band, indicating a significant defect concentration, with an $\mathrm{I}_{\mathrm{D}} / \mathrm{I}_{\mathrm{G}}$ ratio of 1.11 ; while the annealed graphene does not display an observable D-band $\left(\mathrm{I}_{\mathrm{D}} / \mathrm{I}_{\mathrm{G}}\right.$ ratio of 0$)$, indicating the elimination of defects due to the heat treatment. The presence of a 2D-band $\left(\sim 2700 \mathrm{~cm}^{-1}\right)$ in annealed graphene indicates a degree of graphitization, further contributing to the reduction in specific surface area. This demonstrates a direct relationship between defect concentration and specific surface area in graphene powders, and by extension a direct relationship between defect concentration and iodine sorption capacity. 

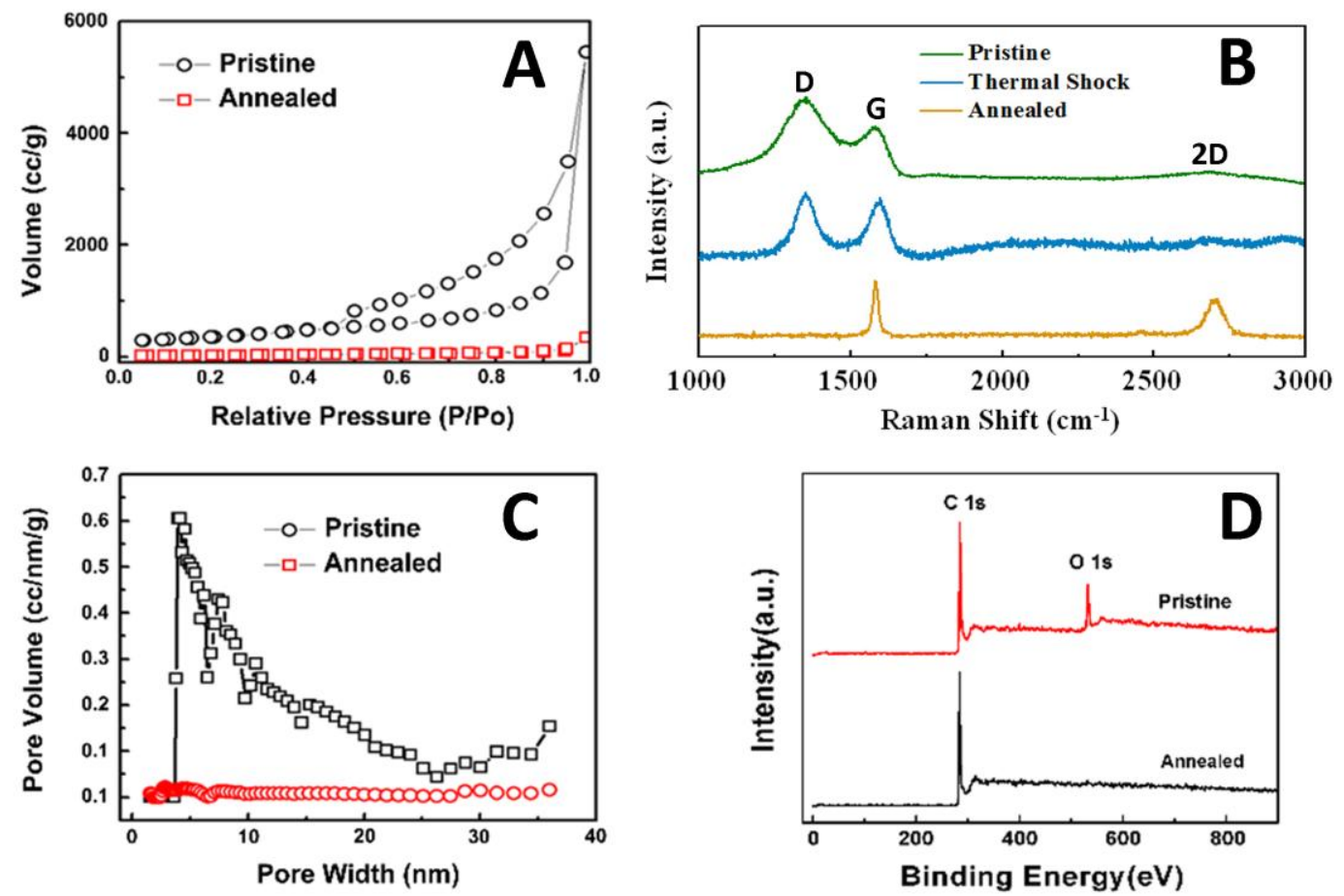

Figure 2. Characterization of selected graphene powders. (A) BET surface area analysis (B) Raman spectroscopy (C) Pore size distribution (D) XPS

The pore size distribution and concentration of the graphene powders (Figure 2C) followed a similar trend as observed between specific surface area and defect concentration, with pores both increasing the specific surface area and acting as adsorption sites for iodine. This is exemplified through the disparity between the pristine and annealed graphene powders in these categories. The heat treatment effectively eliminates defects and pores from the pristine graphene, resulting in a severe loss of iodine sorption capacity.

The role of functional groups in the physisorption of iodine on graphene powders was also investigated. Differences in functional group concentrations on graphene powders are best observed through their relative carbon and oxygen contents ( $\mathrm{C}: \mathrm{O}$ ratios) obtained via XPS measurements (Figure 2C). No relationship was observed between oxygen functional group concentration and the rate of iodine uptake or the maximum sorption capacity of iodine, with specific surface area and defects being the primary factors in both the linear uptake rate and the maximum iodine sorption capacity in graphene powders. 

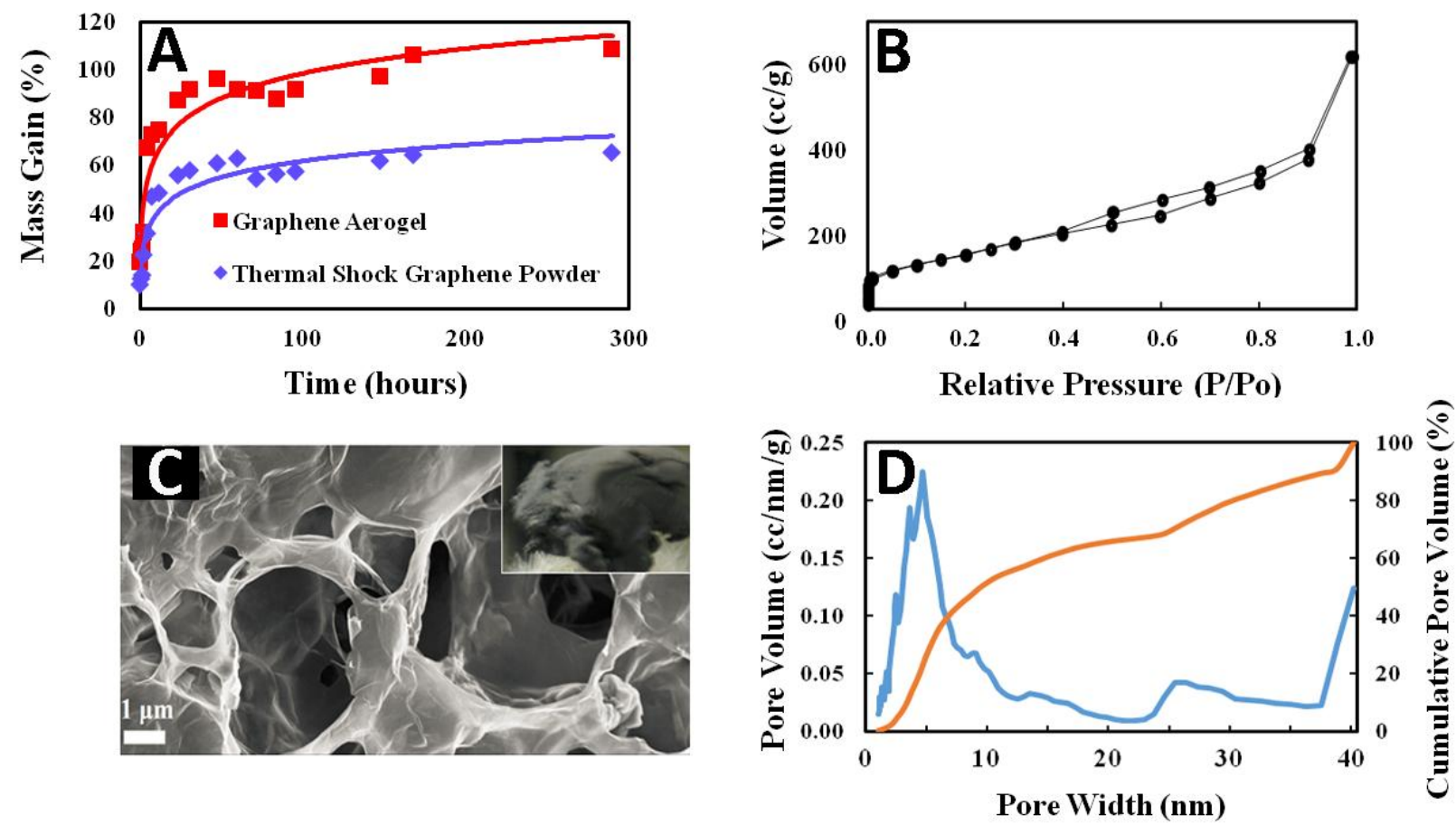

Figure 3. (A) Iodine uptake of graphene aerogel as compared to graphene powder; (B) $\mathrm{N}_{2}$ adsorption desorption isotherm for graphene aerogel; (C) SEM image of graphene aerogel porous structure, optical image of graphene aerogel (inset); and (D) Pore size distribution of graphene aerogel.

By a hydrothermal approach from GO solution, graphene aerogel was prepared and tested as the adsorbent material for iodine capture. Graphene aerogels have demonstrated an improved iodine sorption capacity (> 100\% mass gain) as compared with pristine graphene powders with a high specific area $\left(1272 \mathrm{~m}^{2} \mathrm{~g}^{-1}\right)$, and thermal shock graphene powders $\left(400 \mathrm{~m}^{2} \mathrm{~g}^{-1}\right)$ [18]. (See the iodine uptake curve for graphene aerogel in Figure 3A). BET measurement (Fig. 3B) of graphene aerogel also show a very high surface area up to $\left(508 \mathrm{~m}^{2} \mathrm{~g}^{-1}\right)$, suggesting great potential of graphene aerogel as an advanced absorbent materials. The increased iodine sorption capacity observed in graphene aerogel despite a relatively-lower specific surface area, as compared to pristine graphene, is indicative of a structural factor, attributed to the pore shape and size of the highly porous graphene aerogel (Figure 3C). Specifically, over 50\% of the pore volume and $85 \%$ of the pore surface area are contributed by pores under $10 \mathrm{~nm}$ in width (see Figure 3D and supporting information). This demonstrates while there are larger pores in the aerogel structure, they contribute very little to the overall pore volume and specific surface area of the bulk 
material. The pore profile for graphene aerogels was best fit by a cylindrical pore non-local density functional theory (NLDFT) equilibrium model, as opposed to the slit pore model the graphene powder samples followed. While surface area and defect concentration may dominate the maximum iodine adsorption capacity and kinetics as determined from the powder samples, the pore size and structure may affect the iodine adsorption process as well, in which a dedicated balance between iodine adsorption and desorption is achieved under the saturated testing envirionment. The macropores of the graphene aerogel enable rapid diffusion of the gas molecules such that large surface area of the aerogel can be accessible. On the other hand, the dominate mesopores less than $10 \mathrm{~nm}$ may help to confine adsorbed iodine, consistent with the thermal stability testing of the iodine-loaded samples. The unique pore structure (meso- and micron-pores) is thought to improve not only the maximum sorption capacity of iodine, but the thermal stability of adsorbed iodine, while maintaining identical sorption kinetics at the initial stage as observed in graphene powders.

We further studied the effects of temperature on iodine uptake capacity and adsorption kinetics (see Figure 4) of the graphene powders. No significant change in the maximum iodine uptake capacity was observed at elevated temperatures (Figure 4A); however significant increases in the sorption rate were observed. The linear sorption rate in pristine graphene powders drastically increased with temperature, with $63.6 \% / \mathrm{h}$ observed at $70{ }^{\circ} \mathrm{C}$, and $22.8 \% / \mathrm{h}$ observed at $50{ }^{\circ} \mathrm{C}$, as compared to the $6.8 \% / \mathrm{hr}$ observed at $25{ }^{\circ} \mathrm{C}$. The mass gain upon iodine adsorption also saturated within 4 hours at $70{ }^{\circ} \mathrm{C}$. While the uptake rate dramatically increased, the maximum sorption capacity remained unchanged within the experimental error. These results indicate that the effect of temperature on the performance of graphene-based iodine sorbents is primarily on the sorption kinetics in which greatly-enhanced adsorption kinetics occurs for iodine uptake with increased temperature. By fitting the linear iodine uptake rates to Arrhenius' equation [19]:

$$
k=A e^{-E a / R T}
$$

where $\mathrm{k}$ is the linear sorption rate, $\mathrm{A}$ is the pre-exponential factor, $E_{a}$ is the activation energy, $\mathrm{R}$ is the universal gas constant, and $\mathrm{T}$ is the temperature. The apparent activation energy of iodine adsorption can be determined by plotting $\ln (\mathrm{k})$ against 1/T (as shown in Fig. 4B):

$$
\ln k=-\frac{E_{a}}{R} \frac{1}{T}+\ln A
$$



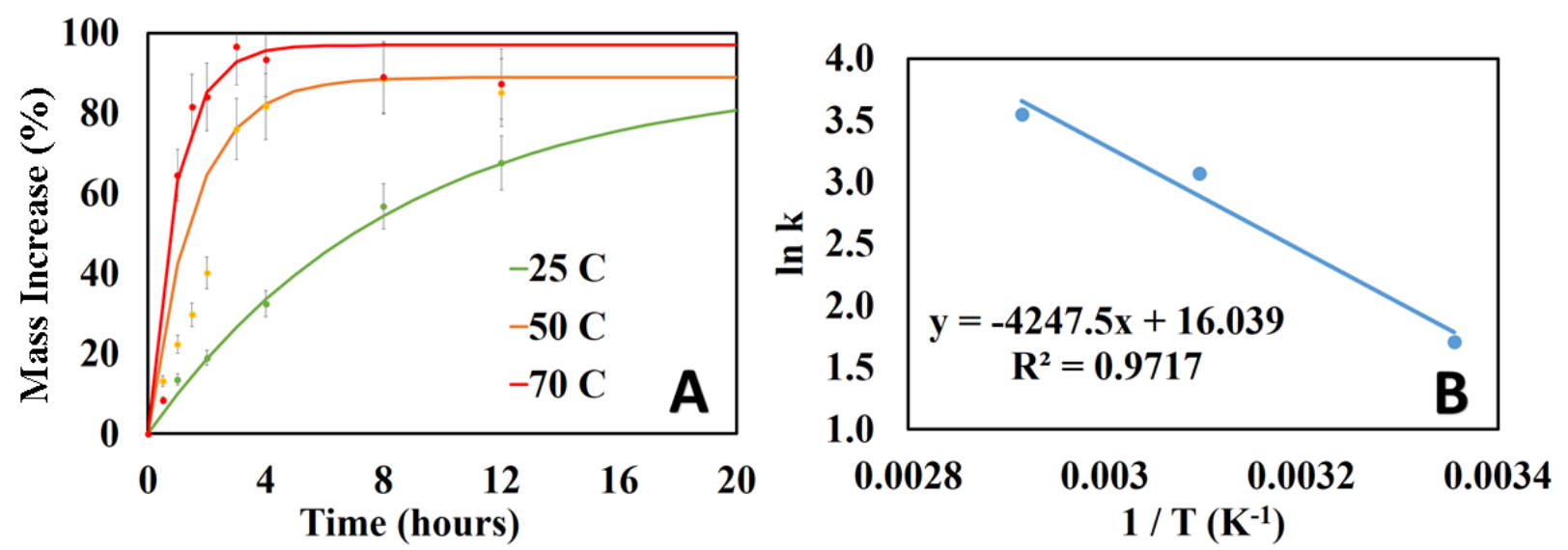

Figure 4. (A) Iodine uptake of pristine graphene at elevated temperatures (B) Arrhenius plot of $\mathrm{I}_{2}$ uptake.

This enables the graphical determination of the apparent activation energy, calculated to be $70.63 \mathrm{~kJ} / \mathrm{mole}$. Incorporating the energy release associated with iodine's deposition (61.1 $\mathrm{kJ} / \mathrm{mole}$ ) yielded a total adsorption energy $\left(E_{a d s}\right)$ of $131.73 \mathrm{~kJ} / \mathrm{mole}\left(1.365 \mathrm{eV} / \mathrm{I}_{2}\right)$. This value is in excellent agreement with density functional theory (DFT) calculations on the iodine-graphene system, which found the $E_{a d s}$ to be between 1.21 and $1.265 \mathrm{eV}$ [20,21]. This also agrees with prior work, stating the iodine-graphene interaction has an ionic contribution, and is caused by charge transfer between the iodine and graphene [22].
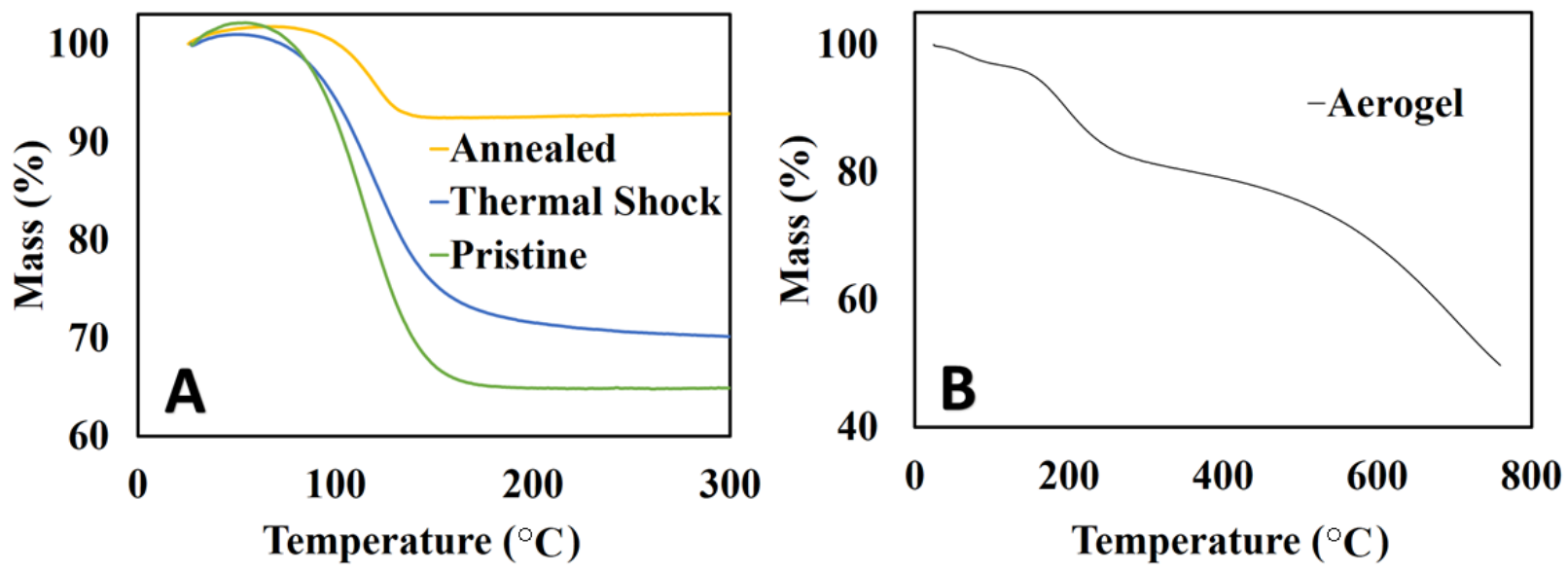

Figure 5. Thermogravimetric Analysis for (A) Graphene powders (B) Graphene aerogels. 
The weight gain of the iodine-loaded graphene samples and their thermal stability were further tested by TGA (Figure 5). A weak bonding between the $I_{2}$ molecules and the graphene structure can be identified, which reinforces the asserted physisorption of the $I_{2}$ on the powders. The sharp mass losses before $200{ }^{\circ} \mathrm{C}$ agree with prior DFT calculations on graphene-halogen adsorption, indicating a dependence on van der Waals forces to stabilize the system despite having a significant ionic contribution [21]. The weight loss is consistent with the iodine uptake results (Fig. 1). This may limit the practicality of implementation of unfunctionalized graphene powders as absorbents in waste streams below a temperature of $200{ }^{\circ} \mathrm{C}$ for iodine capture.

The enhanced thermal stability of graphene aerogels as demonstrated by TGA results (Figure 5B) suggest the same mechanisms improving the sorption capacity allow for enhanced retention of physisorbed iodine, in which the highly-confined meso-pores in the threedimensional macroscopic graphene aerogels allows the confinement of absorbed iodine. The most notable feature of this TGA curve is the lack of a decisive iodine release temperature, a significant departure from the sharp mass losses before $200{ }^{\circ} \mathrm{C}$ observed in powdered samples. The lack of a temperature for major iodine release suggests another mechanism for the capture of physisorbed iodine in graphene aerogels. The mass decrease to $80 \%$ demonstrates a loss similar to that observed in powders, but the gradual decrease from $200{ }^{\circ} \mathrm{C}$ to $500{ }^{\circ} \mathrm{C}$ may demonstrate the migration of iodine contained in the mesoporous structure; while the more significant release of iodine occurs within the temperature range of 500 to $750{ }^{\circ} \mathrm{C}$.

Upon the capture of iodine off-gas from the spent fuel processing plant, it is of necessity to confine the iodine into durable waste forms for direct deposition. At first glance, the weak bonding observed with graphene powders and the nature of physisorption present a challenge in direct consolidation of the iodine-absorbed graphene into a durable waste form material. However, the exceptional maximum sorption capability and extremely fast kinetics present a unique opportunity of using graphene-based materials as absorbents for capturing iodine not only for direct consolidation, but as an intermediate storage medium for ${ }^{129} \mathrm{I}$ in spent nuclear fuel reprocessing systems. The physisorption of the iodine potentially allows the recycling of the graphene absorbent at relatively low temperature $\left(<200{ }^{\circ} \mathrm{C}\right)$. Due to the relatively low temperature of iodine release, it is expected that graphene will retain its high specific surface area without undergoing graphitization which occurs at temperatures exceeding $600{ }^{\circ} \mathrm{C}$. This would allow for use in other waste forms, such as lead orthovanadophosphate - iodoapatite 
ceramics, which may have precursors less suitable for spent nuclear fuel reprocessing systems [23,24].

Another possibility is to encapsulate the iodine-loaded graphene into a proven durable ceramic matrix such as apatite [25]. While the incorporation of iodine loaded graphene into a ceramic matrix would prove difficult for conventional densification techniques, novel densification and consolidation techniques such as field-assisted sintering technologies, e.g., spark plasma sintering (SPS), may allow for iodine incorporation into apatite ceramic matrix with minimal iodine loss. This has been demonstrated in our previous work related to iodine waste forms [23,26]. Iodine confinement in a durable ceramic matrix, such as apatite, is a promising path for this work. Recently, our group has decreased the densification temperature of lead vanadate iodoapatite to $350{ }^{\circ} \mathrm{C}$ highlighting the possibility of iodine retention during the incorporation into a durable ceramic matrix. The consolidation of the iodine-loaded graphene into the durable apatite matrix is currently under exploration and will be reported separately.

Table 2. Comparison of iodine-129 sorbent materials capacities and decontamination factors

\begin{tabular}{ccc}
\hline Sorbent Material & Maximum $\mathbf{I}_{\mathbf{2}}$ Content (wt & Decontamination Factor \\
& $\%$ ) & (DF) \\
\hline Pristine Graphene Powder & $45 \%$ & - \\
Graphene Aerogel & $51 \%$ & $250-500$ \\
SnS Chalcogel & $68 \%$ & $10^{2}-10^{5}$ \\
Ag-Exchanged Mordenite & $17 \%$ & $10^{4}$ \\
Ag-Functionalized Silica & & \\
Aerogel & $32 \%$ & \\
\hline
\end{tabular}


This work differs from the previously mentioned approaches to ${ }^{129} \mathrm{I}$ management in that it relies on the physisorption of the gaseous iodine; whereas other approaches such as silverexchanged-zeolites, silver-functionalized aerogels, and chalcogen-based aerogels utilize chemisorption or a chemical affinity for iodine to capture ${ }^{129} \mathrm{I}$. Despite this lack of chemical affinity for binding with iodine, this approach enables significant mass loadings, as demonstrated in Table 2, up to $51 \mathrm{wt} \%$ in graphene aerogels, as compared to the $32 \mathrm{wt} \%$ in silverfunctionalized silica aerogels, and 68 wt \% demonstrated in chalcogen aerogels [17,27]. The improvement in $I_{2}$ sorption capacity demonstrated over silver-based materials are encouraging to the elimination of silver from iodine sorbent materials. It should be noted that while chalcogen aerogels outperformed graphene aerogels in their maximum $\mathrm{I}_{2}$ sorption capacities, the fabrication of such materials may prove difficult for large scale production, in addition to issues associated with consolidation into a durable waste form.

Due to the comparable $I_{2}$ sorption capacities of the graphene-based sorbents, further investigation into the capture efficiency and associated decontamination factor (DF), defined as the amount of iodine present upstream from the sorbent divdided by the amount divided by the amount of iodine downstream from the sorbent, should be conducted to determine if graphenebased sorbents are compliant with EPA regulations regarding breakthrough efficiency and decontamination factor.

Further work regarding graphene-based iodine sorbents should consider the densification of sorbents into durable waste forms, in addition to the performance of sorbents in adsorption beds to meet EPA regulations regarding breakthrough efficiency. Graphene aerogels are expected to perform well in these aspects due to their high mass loadings, physical stability, and impressive thermal stability which may be further enhanced when coupled with novel densification techniques such as spark plasma sintering. This uptake in combination with the rapid sorption kinetics makes graphene-based materials promising candidates for further iodine sorption tests including deep-bed sorption, functionalization, and waste form consolidation.

\section{Conclusion}

In summary, we report graphene-based materials as novel absorbents for iodine absorption with exceptional maximum iodine uptake capacity and kinetics. A direct correlation among specific surface area, defects and $\mathrm{I}_{2}$ sorption capacity has been demonstrated through uptake experiments. Defects in the graphene structure may act as potential binding sites for the 
physisorption of iodine on the surface of graphene sheets. Temperature has been shown to have a direct relationship with the iodine sorption kinetics, with increasing temperature significantly increasing the iodine uptake rate, while having little-to-no impact on the maximum sorption capacity of the graphene. Due to the exceptional iodine sorption capacity demonstrated, graphene-based materials particularly graphene aerogels, are well-suited for further development

as ${ }^{129} \mathrm{I}$ sorbents. The high iodine mass gain ( over $100 \mathrm{wt} \%$ ), improved physical stability as compared to graphene powders, and the enhanced thermal stability well above the boiling point of iodine $\left(184.3{ }^{\circ} \mathrm{C}\right)$ make graphene aerogel a promising candidate for iodine capture and sequestration from spent nuclear fuel reprocessing systems.

\section{Acknowledgements}

This work was financially supported by DOE NEUP (Nuclear Engineering University Program) under award DE-AC07-05ID14517 (iodine adsorption experiment) and a NSF award DMR 1151028 (synthesis of graphene-based absorbents and structural characterization).

[1] Croff A, Alexander C. Decay characteristics of once-through LWR and LMFBR spent fuels, high-level wastes, and fuel-assembly structural material wastes. Oak Ridge National Laboratory, ORNL/TM-7431, 1980.

[2] Whitehead D. The distribution and transformations of iodine in the environment. Environment International. 1984;10(4):321-39.

[3] Kelly J. Assessment of the Technical Basis of 40CFR190. 40CFR190 Briefing, Sandia National Laboratory, March. 2009;25(2009):9.

\section{[4] Todd T, Vienna J. SEPARATIONS AND WASTE FORMS CAMPAIGN} IMPLEMENTATION PLAN. Pacific Northwest National Laboratory, PNNL-21453, 2012.

[5] Haefner DR, Tranter TJ. Methods of gas phase capture of iodine from fuel reprocessing off-gas: A literature survey. Idaho National Laboratory, INL/EXT-07-12299, 2007.

[6] Chapman KW, Chupas PJ, Nenoff TM. Radioactive iodine capture in silver-containing mordenites through nanoscale silver iodide formation. Journal of the American Chemical Society. 2010;132(26):8897-9.

[7] Matyás $\square$ J, Fryxell G, Busche B, Wallace K, Fifield L. FUNCTIONALISED SILICA AEROGELS: ADVANCED MATERIALS TO CAPTURE AND IMMOBILISE 
RADIOACTIVE IODINE. Ceramic Engineering and Science Proceedings: American Ceramic Society, Inc., 735 Ceramic Place Westerville OH 43081 United States; p. 23-32.

[8] Riley BJ, Chun J, Um W, Lepry WC, Matyas J, Olszta MJ, et al. Chalcogen-based aerogels as sorbents for radionuclide remediation. Environmental science \& technology. 2013;47(13):7540-7.

[9] Schedin F, Geim A, Morozov S, Hill E, Blake P, Katsnelson M, et al. Detection of individual gas molecules adsorbed on graphene. Nature materials. 2007;6(9):652-5.

[10] Zhu Y, Murali S, Cai W, Li X, Suk JW, Potts JR, et al. Graphene and graphene oxide: synthesis, properties, and applications. Advanced materials. 2010;22(35):3906-24.

[11] Zhang Y-H, Chen Y-B, Zhou K-G, Liu C-H, Zeng J, Zhang H-L, et al. Improving gas sensing properties of graphene by introducing dopants and defects: a first-principles study. Nanotechnology. 2009;20(18):185504-185511.

[12] Dai J, Yuan J, Giannozzi P. Gas adsorption on graphene doped with B, N, Al, and S: A theoretical study. Applied Physics Letters. 2009;95(23).

[13] Hummers Jr WS, Offeman RE. Preparation of graphitic oxide. Journal of the American Chemical Society. 1958;80(6):1339.

[14] McAllister MJ, Li J-L, Adamson DH, Schniepp HC, Abdala AA, Liu J, et al. Single sheet functionalized graphene by oxidation and thermal expansion of graphite. Chemistry of Materials. 2007;19(18):4396-404.

[15] Jin M, Kim TH, Lim SC, Duong DL, Shin HJ, Jo YW, et al. Facile physical route to highly crystalline graphene. Advanced Functional Materials. 2011;21(18):3496-501.

[16] Xu Y, Sheng K, Li C, Shi G. Self-assembled graphene hydrogel via a one-step hydrothermal process. ACS nano. 2010;4(7):4324-30.

[17] Strachan DM, Chun J, Matyas J, Lepry WC, Riley BJ, Ryan JV, et al. Summary report on the volatile radionuclide and immobilization research for FY2011 at PNNL: Environmental Molecular Sciences Laboratory, Pacific Northwest National Laboratory, Richland, WA (United States). Funding organisation: US Department of Energy (United States); 2011.

[18] Worsley MA, Pauzauskie PJ, Olson TY, Biener J, Satcher Jr JH, Baumann TF. Synthesis of graphene aerogel with high electrical conductivity. Journal of the American Chemical Society. 2010;132(40):14067-9. 
[19] Laidler KJ. The development of the Arrhenius equation. Journal of Chemical Education. 1984;61(6):494-498.

[20] Klintenberg M, Lebegue S, Katsnelson M, Eriksson O. Theoretical analysis of the chemical bonding and electronic structure of graphene interacting with Group IA and Group VIIA elements. Physical Review B. 2010;81(8):085433 (5pp).

[21] Medeiros PV, Mascarenhas AJ, de Brito Mota F, de Castilho CMC. A DFT study of halogen atoms adsorbed on graphene layers. Nanotechnology. 2010;21(48):485701-485708. [22] Rudenko A, Keil F, Katsnelson M, Lichtenstein A. Adsorption of diatomic halogen molecules on graphene: a van der Waals density functional study. Physical Review B. 2010;82(3):03542 (7pp).

[23] Yao T, Lu F, Sun H, Wang J, Ewing RC, Lian J. Bulk Iodoapatite Ceramic Densified by Spark Plasma Sintering with Exceptional Thermal Stability. Journal of the American Ceramic Society. 2014;97(8):2409-12.

[24] Lu F, Yao T, Xu J, Wang J, Scott S, Dong Z, et al. Facile low temperature solid state synthesis of iodoapatite by high-energy ball milling. RSC Advances. 2014;4(73):38718-25. [25] Guy C, Audubert F, Lartigue J-E, Latrille C, Advocat T, Fillet C. New conditionings for separated long-lived radionuclides. Comptes Rendus Physique. 2002;3(7):827-37.

[26] Matyáš J, Engler R. Assessment of Methods to Consolidate Iodine-Loaded SilverFunctionalized Silica Aerogel.Pacific Northwest National Laboratory, PNNL-22874, 2013.

[27] Riley BJ, Pierce DA, Chun J, Matyás $\square$ J, Lepry WC, Garn TG, et al. PolyacrylonitrileChalcogel Hybrid Sorbents for Radioiodine Capture. Environmental science \& technology. 201;48(10):5832-9. 